\title{
Development of Hybrid Product Breakdown Structure for NASA Ground Systems
}

\author{
Mark W. Monaghan, SAIC, MS: LX-SAIC, Kennedy Space Center, FL 32899 mark.w.monaghan@nasa.gov \\ Robert J. Henry, NASA, MS: LX-S2, Kennedy Space Center, FL, 32899 robert.j.henry@nasa.gov
}

\begin{abstract}
The Product Breakdown Structure is traditionally a method of identification of the products of a project in a tree structure. It is a tool used to assess, plan, document, and display the equipment requirements for a project. It is part of a product based planning technique, and attempts to break down all components of a project in as much detail as possible, so that nothing is overlooked.
\end{abstract}

The PBS for ground systems at the Kennedy Space Center is being developed to encompass the traditional requirements including the alignment of facility, systems, and components to the organizational hierarchy. The Ground Operations Product Breakdown Structure is a hybrid in nature in that some aspects of a work breakdown structure will be incorporated and merged with the Architecture Concept of Operations, Master Subsystem List, customer interface, and assigned management responsibility. The Ground Operations Product Breakdown Structure needs to be able to identify the flexibility of support differing customers (internal and external) usage of ground support equipment within the Kennedy Space Center launch and processing complex.

The development of the Product Breakdown Structure is an iterative activity initially documenting the organization hierarchy structure and relationships. The Product Breakdown Structure identifies the linkage between the customer program requirements, allocation of system resources, development of design goals, and identification logistics products. As the Product Breakdown Structure progresses the incorporation of the results of requirement planning for the customer occurs identifying facility needs and systems. The mature Product Breakdown Structure is baselined with a hierarchical drawing, the Product Breakdown Structure database, and an associated document identifying the verification of the data through the life cycle of the program/product line.

This paper will document, demonstrate, and identify key aspects of the life cycle of a Hybrid Product Breakdown Structure. The purpose is to show how a project management and system engineering approach can be utilized for providing flexible customer service in an evolving manned space flight launch processing environment.

\section{WHAT IS A PRODUCT BREAKDOWN STRUCTURE}

The product breakdown structure is often described as a representation of tasks or measurement points tracked to the lowest level of the production lifecycle of the product creation. The PBS identifies the individual products necessary for the product. The PBS includes the hardware, software, and information items necessary to complete the project. The information items identified in the PBS can be essential documents, critical databases, and configuration drawings necessary to build or develop the product.

The PBS is defined differently depending on the application or the organization developing the PBS. There is a project management application of the PBS and there is a system engineering application. Both develop the PBS at the same timeframe of a project.

The PBS is developed during the developmental timeframe of the product. Specifically when the technical requirements are baselined. During the developmental timeframe the PBS is used to categorize the hardware, software, and informational products necessary as the development of the product proceeds. The evolution of the PBS through the life cycle of product development insures that the necessary products needed are identified and categorized. Each individual PBS identified product can have its own developmental process. Therefore, the PBS identifies individual production metrics necessary.

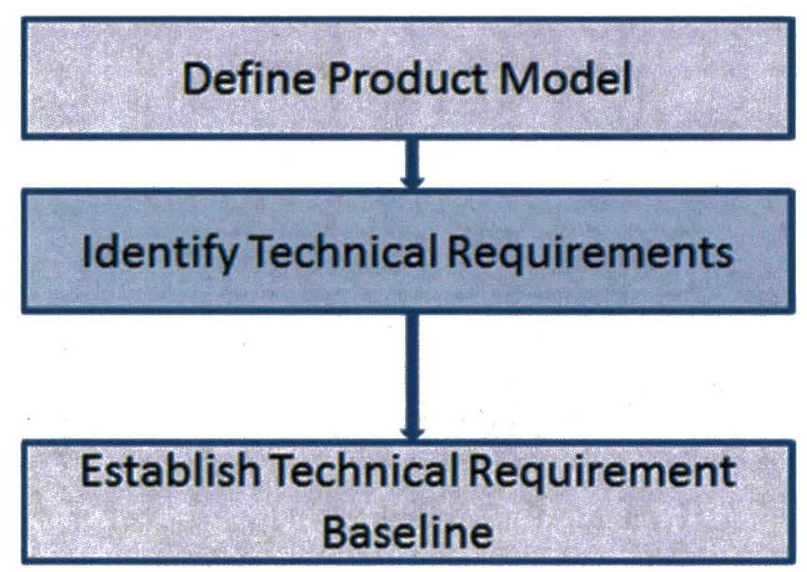

Figure 1: Developmental Decomposition Process

The individual PBS metrics provide traceability throughout 
the developmental lifecycle. In relation to the development of the technical requirement baseline other products are necessary to track requirements, verification, testing, and validation. The individual PBS identifies the item whether it is hardware, software, or informational necessary to baseline the production.

In the PBS the responsibility for the individual hardware, software, and information product development needs to be identified. The organization responsible for the PBS identified metric provides traceability to performance of the task. The PBS as a result becomes the integration toll for the project identifying the responsible organization to deliver the identified metric (i.e. hardware, software, or informational) and all related data associated with it.

The PBS becomes the single source for identification of hardware, software and the information products. As, a result is a top-down High level matrix of the products and organizations necessary to baseline the project.

The PBS is not the Work Breakdown Structure (WBS) but the PBS is contained within the WBS. The WBS contains the financial accounting information and assigns budgetary goals for the organization [1].

\section{HOW PBS RELATES TO PROJECT MANAGEMENT}

A project is a limited time endeavor utilized to build a specific product, perform a specific function, and have a specific goal. The implication is that a project has a specific beginning and a specific end. A project development structure used to build unique products defines the project scope. The project scope identifies the project justification, product, deliverables, and objectives.

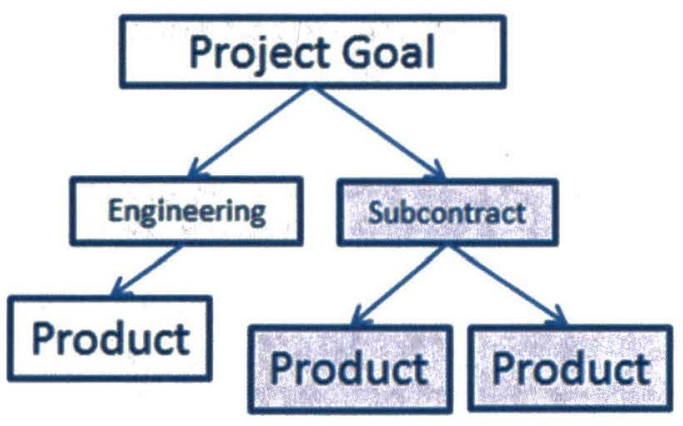

Figure 2: PBS as developed by Project Management

The PBS is used to identify the project deliverables at a summary level. It provides the hardware, software, and information listing for the completion of the project. The PBS further is used to identify the organization responsible for the delivery of the hardware, software, and informational items. The scope of the deliverable needs to address by the project as well as, the integration of when the deliverable is required (its timeline) and the interface of the individual deliverable to the entire project.

The PBS aids the project manager in the identification of the responsible organization and the deliverable necessary. The PBS is used in large and complex projects where a WBS has been identified to define budgetary applications [2]-[3].

\section{HOW PBS RELATES TO SYSTEM ENGINEERING}

The development of the PBS in a system engineering development cycle is an iterative process that involves a connection between the concept of operations (ConOps) and requirements. The ConOps defines the scope of the system performance within the operational characteristics that it is being utilized. The ConOps is used (from a PBS outlook) to identify the subsystems necessary, how they interact, and system function to be performed in the process being defined. The requirements are derived from performance allocations, high level system interfaces, operations required to be performed, and the supportability needs of the subsystems. The iterative process develops the stakeholder requirements into operational concepts and the products (i.e. hardware, software, and informational) needs to produce the goal. As each of the system products are developed or changed the reflection of that change should enhance the PBS decomposition. Summarily, the PBS identifies the hardware, software, and informational needs to develop or process the product through the system based on the concept of operations or requirement defined by the customer.

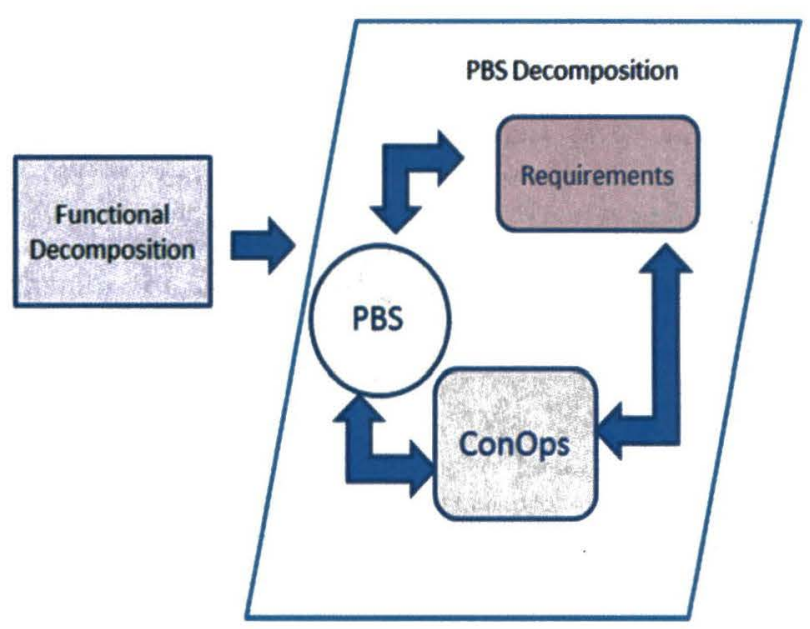

Figure 3: PBS as developed by System Engineering

The PBS relationship to system engineering can be identified to three basic functional goals. 
- Translate top level requirements to functions

- Identify functional interfaces into ConOps

- Allocate functions in to the PBS

For the system engineer the PBS functions as the conduit to transform requirements and ConOps to the responsible engineering level to deliver the hardware, software, and informational items [1, Sec. 4.0].

\section{THE MERGER BETWEEN PROJECT ENGINEERING AND SYSTEM ENGINEERING USE OF THE PBS}

The project manager uses a PBS to identify the project deliverables by various groups, departments, or responsible parties. Therefore the PBS to the project manager is the function of the responsible group and the product. The project manager either within the WBS or external as the PBS identifies the responsible group and product (i.e., hardware, software, or informational).

Where:

$$
P B S_{P M}=f(G, P)
$$

$P B S_{P M}$ is the product breakdown structure for project management.

$\mathrm{G}$ is the various groups (i.e. Engineering, subcontracts)

$\mathrm{P}$ is the product deliverable.

The system engineer uses the PBS to identify how requirements and concept of operations relate to the system level functions. The system engineering identifies the PBS as it relates to the development of requirements and the concept of operations as well as the responsible group or organization to deliver the hardware, software, or informational product.

Where:

$$
P B S_{S E}=f(R, C, G)
$$

$P B S_{S E}$ is the product breakdown structure for system engineering.

$R$ is Requirements

$C$ is the Concept of Operations (ConOps)

$G$ is the various groups (i.e. Engineering, organization)

The merger of the two views of a PBS can be made to determine in a complex system first by, identification of various groups to provide deliverables, and second, to identify how operations relate to the individual systems. The intersection of $\mathrm{PBS}_{\mathrm{PM}}$ and $\mathrm{PBS}_{\mathrm{SE}}$ is becomes the engineering group responsible.

Therefore:

$$
P B S_{P M} \cap P B S_{S E} \approx f(G)
$$

The common identifying function in both the project management and the system engineering application of the PBS is the engineering or responsible group for the delivery of the product or service [4]-[5].

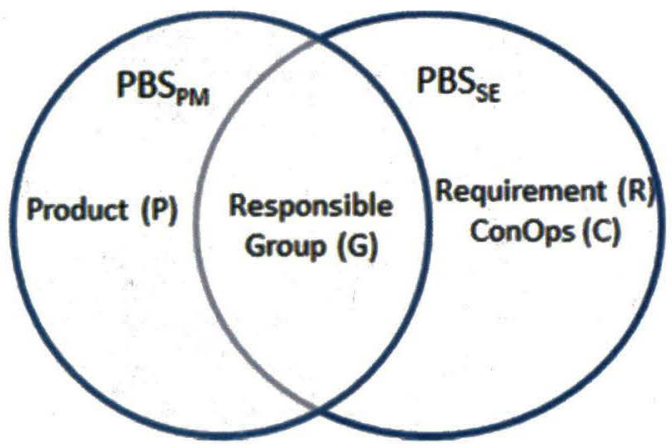

Figure 5: Intersection of $\mathrm{PBS}_{\mathrm{PM}}$ and $\mathrm{PBS}_{\mathrm{SE}}$

The resultant PBS is based on the organization of the component product or service and its support to the project product description. The PBS provides the relationship from the lowest level product or service to the top level project product description as defined by the product owner.

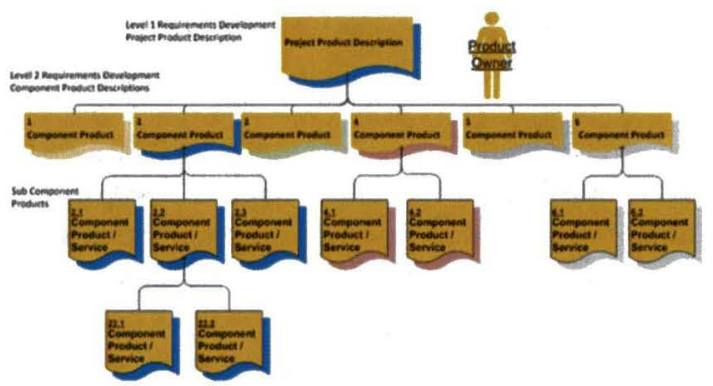

Figure 4: Composition of the PBS

Level 1 provides the top level requirements development project product description. Level 1 is the product development goal. Level 2 defines the component products, service, or defined process supporting the level 1 developmental goal. Component products are define the sub-component products or service required to complete the level 2 component product.

\section{GROUND SYSTEMS DEVLOPEMENT AND OPERATIONS APPROACH TO PBS}

In April of 2012 NASA established the Ground Systems Development and Operations (GSDO) program as the official program for the development of the ground systems and infrastructure for the Space Launch System (SLS), the Orion Multipurpose Crew Vehicle (MPCV), and future emerging users. GSDO program provides pre-launch 
processing, launch site support, and recovery resources. GSDO is center at the Kennedy Space Center (KSC) in Florida. GSDO is part of the Human Exploration and Operations Mission Directorate (HEO) and the Exploration Systems Development (ESD) which establishes the top level requirements and defines the mission objectives for GSDO [6].

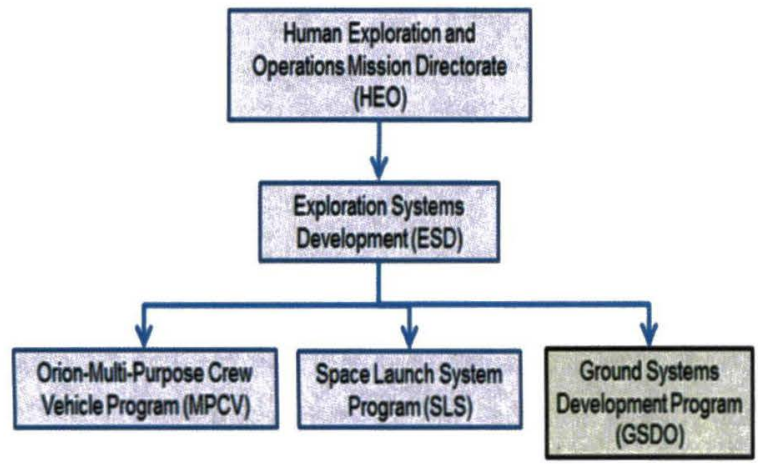

Figure 6: NASA Human Exploration Organization

GSDO program has requirements established by the ESD. The requirements provided by the ESD define the operational goals for GSDO. In addition to the operational requirements the ESD has a set of technical process metrics to report. Cross program teams provide interaction between the three programs.

The GSDO program operates as a project team with a systems engineering definition and is hybrid combination of both functional concepts. GSDO as a system engineering centered project has requirements to follow based on the customer (ESD). GSDO then establishes ConOps for the operation of the program based on the requirements. The individual subsystems utilized in the development of the GSDO PBS are identified in the Master Subsystem List (MSL). The definition of the individual subsystems is consistent with the assignment of the individual engineering teams.

There is no specific document requirement for a Product Breakdown Structure (PBS) in the NASA guide for programs and project management it identifies a need for NASA program to establish a policy to apply disciplined, collaborative processes, and systems to identify, acquire, and control product data throughout the project life cycle. Also, there is no specific requirement identified by the NASA Chief engineering office to develop a PBS for the program. The PBS is discussed in detail in the NASA Systems Engineering handbook but as good systems engineering practice [7] [8].

\subsection{GSDO Program Project Organization Structure}

In order to manage the GSDO program a project management organizational structure was created to identify various levels of project reasonability. The large complexity of the project required that the responsibilities for the program be defined to separate levels. GSDO management has an analysis integration team (AIT) overseeing the various analysis and project processes. The Integrated Product Team (IPT) is divided into program areas needed to complete the project. Within the IPT are Element Integration Teams that are assigned to specific developmental products. These developmental products are identified to specific areas, responsibilities, may encompass a single production location, or provide services to many areas.

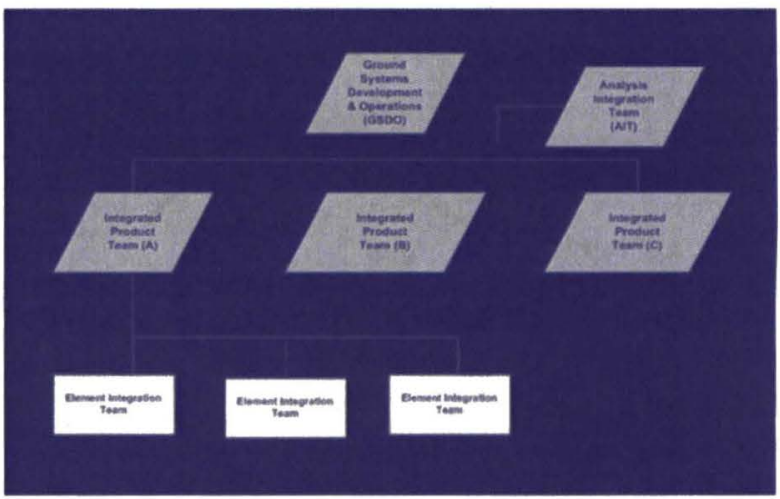

Figure 7: GSDO Project Organization

\subsection{Work Breakdown Structure (WBS)}

The WBS as used in the GSDO program is used to define budget and allocations to the various GSDO projects and program levels. The WBS is utilized to approve developmental, operational, and logistical authorizations. The WBS is detailed to the IPT and is some cases the EIT level as identified by the IPT.

\subsection{Assets Capabilities Document (ACD)}

The ACD was developed to assist GSDO, SLS, MPCV, and Commercial Programs in the familiarization of capabilities provided by GSDO Program assets. It combines the highlevel capabilities of the GSDO assets into one consolidated document including those required to support ground vehicle processing operations that are non-mission specific. In addition, the ACD provides references to the detailed drawings and figures where additional design data can be found [7].

\subsection{Architectures and Concept of Operations Document (ACO)}

ACO Document describes the GSDO architecture in an operational context. This includes characteristics of the ground system, interfaces between GSDO and other programs, including commercial programs, nominal and contingency operational scenarios, and system performance expectations. Test flights for any vehicle will mirror this concept of operations as closely as possible [7]. 


\subsection{Master subsystems List (MSL)}

This document establishes a Ground Systems Development and Operations (GSDO) Program list of the Kennedy Space Center (KSC) Subsystems that will receive requirements from the GSDO Elements. In addition, this document defines the design certification level which the subsystem is required to be verified.

\subsection{GSDO PBS Requirements}

The GSDO PBS requirements are aligned with the GSDO $\mathrm{ACD}, \mathrm{ACO}$, and MSL for the management responsibility and accountability. The GSDO PBS has been developed with the top level being defined by the needs of the project product description contained within the development of the requirements documents.

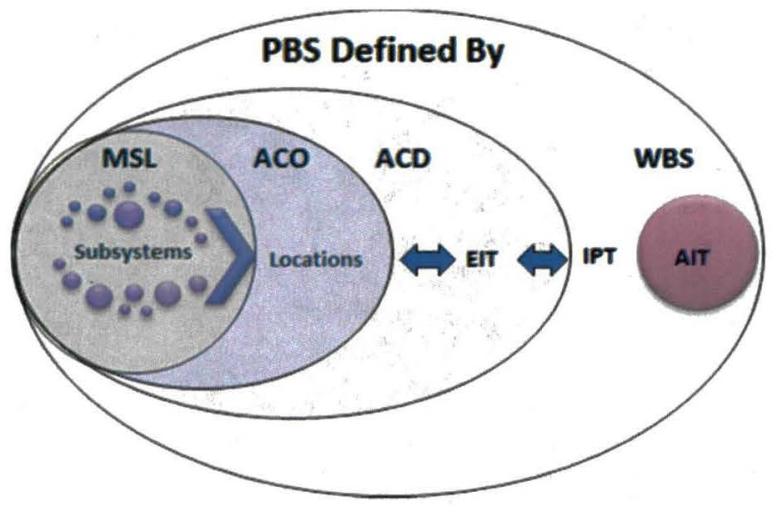

Figure 9: GSDO PBS Supporting Documents

\section{GSDO PBS STRUCTURE}

The IPT represents the level 2 part of the program with the EIT responsible physical locations or facilities. The systems/subsystems contained within the respective location or facility is managed by the program through the EIT. The subsystems contain the equipment or components that encompass the subsystem.

As requirements are established the EIT is responsible for establishing requirements for the individual subsystems' to meet. The subsystems are defining the equipment or components that make-up the subsystem within the location or facility identified by the requirement. The PBS is the single point that identifies the System Engineering and Integration (SE\&I) product that will provide this overall logical view of the interrelationship between equipment, subsystems, facilities, and EIT within the GSDO Program.

The PBS is linked to the lowest level (configuration items, Line Replaceable Units (LRU), equipment, etc.) as defined by the responsible Design Engineering group. The PBS also links to data base products that document the association between the subsystem and the facility. This includes the facility to which the subsystem is located and the EIT responsible for the facility. The linkages to Design/CAD Data, requirements data, and risk data, manufacturing data work instructions, operations, and test data will be identified at the top drawing level. The GSDO PBS by providing this linkage to will associate subsystem design or sustaining engineering with the facility and therefore the product structure required for the project.

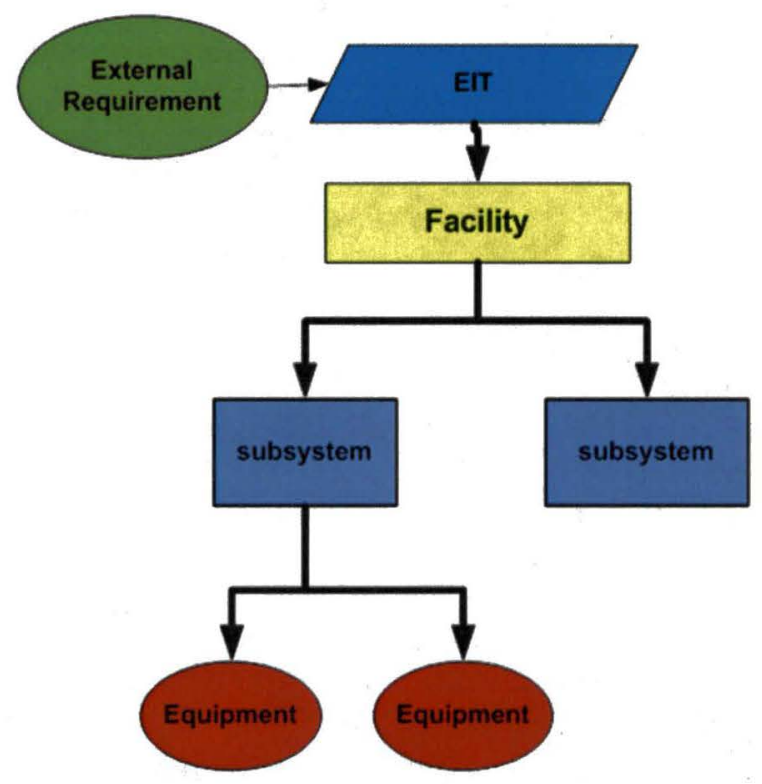

Figure 8: GSDO PBS Structure

The various other related activities such as Verification \& Validation, Logistics, Ground Operations Planning \& Development (GOPD), Configuration Management, and Work Order Control can use the PBS as a baseline document to identify program requirements for a specific location as managed by the EIT. The use of a single top level drawing as identified by the PBS would provide a single resource point to track and document the subsystems throughout the life cycle of the program.

\section{GSDO PBS DEVELOPMENT}

The GSDO PBS development activity for the System Requirements Review (SRR) was to define and document the hierarchical of the structure of the PBS. As GSDO progresses to the Preliminary Design Review (PDR) the PBS it will incorporate the requirement planning for the subsystems and identify the component or equipment that make-up the respective subsystems by the top level drawing. At the GSDO Critical Design Review (CDR) the PBS will be baselined with the top level drawing, database, or an associated document identifying the verification of the data through with the life cycle of the program/product line.

\section{GSDO PBS SUMMARY AND CONCLUSION}

Once the PBS is complete; it will be a useful tool for 
communicating what needs to be built. It also provides a linkage between the program, design, and logistics products. The IPT, EIT, and Engineering, will take advantage of logical organization and access to information. The PBS will show the location capability, subsystems located in the location, and the supporting subsystem top level drawing. The GSDO PBS provides traceable product information (e.g., data, documents) throughout life-cycle (i.e., design, manufacturing, verification and validation, assembly/integration, launch). As an operations tool the PBS will vary with missions and will be the single source to quickly locate subsystem design information.

\section{REFERENCES}

1. NASA Systems Engineering Handbook, NASA Special Publication SP-2007-6105 rev 1, 2007

2. IEEE Guide Adoption of PMI Standard: A Guide to the Project Management Body of Knowledge, IEEE Standard 1490, 2003

3. T.C. Belanger. 1997 Successful Project Management, American Management Association.

4. The National Shipbuilding Research Program: Product Work Breakdown Structure, U.S. Department of Transportation Maritime Administration NSRP-0164, 1982

5. C.E. Ebeling. 2005. An Introduction to Reliability and Maintainability Engineering. Waveland Press

6. "Program/Project Formulation Authorization Document: Ground Systems Development and Operations Program", NASA, unpublished.

7. NASA Program and Project Management Process and Requirements, NASA Procedures and Guidelines NPG 7120.5B, 2007

8. NASA Systems Engineering Processes and Requirements, NASA Procedural Requirements NPR 7123.1A, 2012

\section{BIOGRAPHIES}

Mark W. Monaghan

Bldg. M7-0355

MS: LX-SAIC

Kennedy Space Center, FL, 32899, USA

e-mail: mark.w.monaghan@nasa.gov

Mark W. Monaghan received his Ph.D. in Applied Decision Science from Walden University, a Master's degree from Embry-Riddle Aeronautical University and Bachelor's degree from the University of Minnesota-Duluth. Mark is a Reliability Engineer with SAIC at NASA Kennedy Space Center, FL. As a part of the Kennedy Space Center Reliability Maintainability and Availability (RMA) team, Dr. Monaghan works with multiple engineering teams to evaluate and increase the operational and inherent availability of the systems. He is a senior member of Institute of Electrical and Electronic Engineers
(IEEE) Industrial Application Society (IAS) and Reliability

Society. He is also a member of American Institute of Aeronautics and Astronautics (AIAA), American Society for Engineering Management (ASEM), Institute for Operations Research and the Management Sciences (INFORMS), and the American Society for Quality (ASQ) Reliability Society.

Robert J. Henry

Bldg. M7-0355

MS: LX-S2

Kennedy Space Center, FL, 32899, USA

e-mail: Robert.j.henry@nasa.gov

Robert J. Henry received his Master of Business Administration (M.B.A.) from Florida Institute of Technology and Bachelor's degree from the University of Illinois at Chicago. Robert is currently a Systems Engineer with National Aeronautics and Space Administration (NASA) working in the Program Integration Division of the Ground Systems Development and Operations (GSDO)

Program at KSC, FL. Previously he has held positions with NASA as Mission Assurance Manager and Vehicle Systems Engineer for the Launch Services Program (LSP) at KSC. 